\section{Questión}

Periodismo / Comunicación ISSN 1669-6581
- Av. $44 \mathrm{~N}^{\circ} 676,1^{\circ}$ piso

CP 1900 - La Plata - Argentina

(i) www.perio.unlp.edu.ar/question

Una olla cargada de futuro

Ana Lacunza

https://doi.org/10.24215/16696581e402

\title{
Una olla cargada de futuro
}

\section{A pot loaded with the future}

\author{
Ana Lacunza \\ militante social, coordinadora del apoyo escolar en el barrio El Progreso \\ analacunza@gmail.com
}

"Hablar de ternura en estos tiempos de ferocidades no es ninguna ingenuidad. Es un concepto profundamente político. Es poner el acento en la necesidad de resistir la barbarización de los lazos sociales que atraviesan nuestros mundos."

Fernando Ulloa

Hacía unos pocos días que se había declarado el inicio de la cuarentena; al principio creímos que iba a durar poco tiempo... unos días para estar en casa y ver como venía la mano con el coronavirus en otros países. En el barrio de La Casita del Niño Arco Iris, en Villa Elisa, todo el tema sonaba muy lejano: acá nadie viaja a Europa, muchos ni siquiera vieron nunca el mar, ni la nieve.

Ese día Lucía, una mamá que lleva sus chicos al apoyo escolar me mandó un mensaje por WhatsApp: "Ana... que te parece si cocinamos en la casita para los que más necesitan. Yo no te digo que no necesito, pero cuando salgo veo que hay más familia o chicos que necesitan la comida. Yo estoy dispuesta a cocinar", me decía.

Era sabido que, si la cuarentena se hacía muy larga, al que trabajaba por el jornal del día se le iba a hacer cuesta arriba poner el plato de comida en la mesa, y en el barrio casi nadie cuenta con ahorros. "Difícil que se pueda guardar alguna platita si ni siquiera alcanza para la garrafa", me dijo Lorena. 
Todo se organizó en poco tiempo: en un rato teníamos las alitas de pollo, los fideos y el puré de tomate para el guiso, y cuando empezamos a cocinar llegó Gabriel con dos chorizos colorados. "Si no, no tiene gusto a nada", nos dijo mientras todas aplaudíamos.

Para entregar las viandas no teníamos recipientes descartables, así que organizamos un dispositivo con un fuentón de agua con lavandina para desinfectar el tupper, otro con agua limpia para enjuagarlo y una mesa con repasadores para secar el recipiente y llenarlo con el guiso. Todos se tomaron muy seriamente la distancia de metro y medio y la limpieza de los recipientes y las manos.

Al principio vinieron las mamás que durante el año ya recibían sus viandas o llevaban a sus niños y niñas al comedor de la Casita, pero después comenzaron a sumarse otras familias que habitualmente no necesitaban esta ayuda, como las del Club Infantil El Progreso. Lorena es referente del Club, sus hijos ya están grandes y ahora juegan ahí sus nietos, pero ella siempre está al pie del cañón atenta a las necesidades del barrio. Así que a través de ella nos comunicamos con otras familias para poder darles una mano también.

La mayoría de las trabajadoras y trabajadores del Barrio El Progreso, donde se encuentra la Casita del Niño, trabajan en obras de construcción o en casas de familia haciendo tareas domésticas, y a pesar de que algunas madres debían seguir cobrando, sus empleadores les suspendieron los pagos. "Yo le escribo a mi patrona para ver cuándo me paga y me clava el visto y sin eso yo no tengo nada de nada - nos contó Marlene -. A mi vecina sí le paga, pero medio a las cansadas y con lo que subieron los alimentos no alcanza para nada".

"Acá en el barrio vivimos hace muchos años y estamos acostumbrados a darnos una mano entre todos cuando alguien tiene problemas; no te digo que no haya peleas y chismeríos como en todos lados, pero los que somos de acá desde chiquitos tenemos metida la solidaridad en el cuerpo y no vamos a dejar a un vecino o a una vecina sin comer", me contaba Lorena mientras levantaba la olla para colar los fideos.

La pandemia puso en negro sobre blanco las desigualdades que ya estaban instaladas; los índices de pobreza son números fríos que de tanto repetirlos no conmueven a nadie, pero la verdad en los barrios es que muchas familias viven en muy malas condiciones, con falta de acceso a los servicios, muchas veces se les corta el agua, no hay cloacas, los sueldos son en negro, el acceso a la salud es muy complicado y hay muchas personas adultas que padecen diabetes e hipertensión. 
A esto se suma que las soluciones tecnológicas fueron pensadas para una población que cuenta con acceso a internet, teléfonos con crédito y alfabetización digital, sin pensar que si la opción es comer o cargar el teléfono, como pasa aquí, la respuesta en muy obvia. Estas dificultades se convirtieron en barreras al momento de poder acceder a los beneficios pensados por el gobierno para quienes se quedaron sin ingresos por la cuarentena.

Muchos y muchas de nosotros estamos pensando qué enseñanzas y reflexiones nos quedarán de esta experiencia, y sobre esto estuvimos charlando entre olla y olla. Para Daiana, mamá de siete chicos y trabajadora incasable, "no tendríamos que haber pasado por todo esto para ser solidarios y pensar en el otro; desde hace tiempo tendríamos que haber sido mejores personas, me gustaría que después que pase la pandemia todos hayamos tomado esto como un aprendizaje y seamos mejores, valoremos la vida y pensemos mucho más en el otro".

Isidora está rearmando un grupo de costura para encontrar una fuente de trabajo y aprender un oficio. Todas las tardes se sienta con otras mujeres a coser y a pensar en las cosas que les gustaría hacer cuando termine la cuarentena. "Mi deseo es hundirme en un fuerte abrazo con mis hermanas y demás familia, compartir una reunión con vecinos, disfrutar de un finde con mis nietos en un parque o plaza; también quiero que los niños vuelvan a sus actividades sin miedo pero que tengan conciencia y esto les lleve a una buena reflexión a ellos y más a los adultos. Tengo muchos deseos, no te voy a mentir, pero hoy por hoy desearía volver a festejar un cumpleaños, ver mi casa llena de familia y amigos y, sobre todo, que tengamos salud y no falte nadie", dice. "Espero que no te olvides y nos invites, Doris", le dice Alicia y todas las risas se cuelan entre los rayos de sol del otoño y el sonido de la máquina de coser. Carolina, detrás del tapabocas, se pone un poco triste: "Después de esta cuarentena lo que más deseo es volver a ver a mi mamá y hermanos que viven en Corrientes", dice.

Carolina no es la única que tiene su familia lejos y está sintiendo la distancia. Marlene también extraña a su familia de Paraguay y por momentos se le hace difícil ayudar a su hija con las tareas; ella no está familiarizada con la Historia Argentina, la Primera Junta y el 25 de Mayo. Cuando me pidió ayuda disculpándose por ser de otro país, me quedé mirándola y le dije: “iY cuál es el problema? Yo tampoco sé qué día es el de la independencia de Paraguay".

También Julio, el papá de Cachito, se acercó a la Casita a dar una mano para fabricar lavandina con la materia prima que donó la Universidad Nacional de La Plata. Entre varios vecinos fabricaron 600 litros para repartir entre comedores y merenderos de Villa Elisa y Arturo Seguí. 
Julio trabaja en una Cooperativa Municipal y como su trabajo es esencial no tuvo interrupciones; a él lo que más le preocupa es "la gente que está más necesitada, que en verdad la están pasando mal. Yo, gracias a dios, siempre trabajo mal o bien, pero hay gente del barrio que está peor y hay que ayudarla con lavandina, jabón y mercadería."

Todos andamos buscando recursos, hacemos publicaciones en redes, acudimos a amigos solidarios para que nos ayuden y también nos reunimos con otras Casitas, comedores y merenderos para pensar la crisis juntos, compartir información y reclamar recursos y vacunas antigripales al municipio.

En estas reuniones nos damos el tiempo para pensar en la oportunidad que tenemos para que las cosas sean diferentes en el futuro; creemos que las acciones comunitarias han venido para quedarse, y como nos dijo Karina, de la Casita del barrio El Rincón, "tenemos que pensar proyectos cooperativos de autonomía alimentaria”. En este sentido, un granito de arena aportó Gabriel, docente de nuestros barrios, que consiguió semillas de estación y estuvo con las familias armando pequeñas huertas pensando en el mediano y el largo plazo.

La vida no es fácil en el barrio; sin embargo, la capacidad de resistencia a las dificultades es enorme, la experiencia acumulada por haber pasado otras situaciones difíciles, como la inundación o la crisis del 2001, le dieron valor a la organización comunitaria, que no le escapa al compromiso y se arremanga para ayudar al otro, desarrollando estrategias de comunidad que no se ven en otros espacios y clases sociales.

Me quedo con la reflexión de Isabel, una madre mapuche, lonko de su comunidad y tía de tres niñas que van al apoyo escolar: "Esto es un antes y un después, y el deseo es que puedan entender y sentir desde lo más profundo que podemos vivir un nuevo raquizuan (pensamiento), una nueva kimun (sabiduría) para poder seguir compartiendo a nuestra ñuke mapu (madre tierra), la cual nos contiene a todos sin distinción de clases y de colores llenos de diversidades y así transitar este camino en equilibrio en paz y amor". 